\title{
Enfortumab Vedotin
}

National Cancer Institute

\section{Source}

National Cancer Institute. Enfortumab Vedotin. NCI Thesaurus. Code C114500.

An antibody drug conjug ate (ADC) containing a human monoclonal antibody AGS-22 targeting the cell adhesion molecule nectin- 4 and conjug ated to the cytotoxic agent monomethyl auristatin E (MMAE), via a proprietary enzyme-cleavable linker (AGS-22CE), with potential antineoplastic activity. The monoclonal antibody moiety of enfortumab vedotin selectively binds to nectin-4. After internalization and proteolytic cleavage, MMAE binds to tubulin and inhibits its polymerization, which results in G2/M phase arrest and induces apoptosis in nectin-4 overexpressing tumor cells. Nectin-4, a tumor associated antigen belonging to the nectin family, is overexpressed in a variety of cancers, including breast, bladder, lung and pancreatic cancer. 